\title{
Journalists, PR professionals and the practice of paid news in Central and Eastern Europe: An overview
}

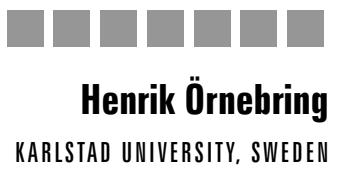

DOI: 10.19195/1899-5101.9.1(16).1

\begin{abstract}
This article maps the practice of paid news in Central and Eastern Europe using a review of previous research and a set of exploratory semi-structured interviews with journalists and PR practitioners across 10 post-communist countries in Central and Eastern Europe $(N=164)$. Paid news refers to the practice of journalists and/or news organizations taking money (often offered through the intermediary of a PR professional or PR company) to write puff pieces for businesses or political interests without indicating that the content is in fact paid for, i.e. a form of corruption of both journalism and PR. This presentation suggests that the existence of the practice is to a great extent systemic, as both journalists and PR professionals are part of a common "culture of corruption" and thus the continued existence of the practice is also a de-professionalizing influence on both occupations, where representatives of both spheres have strong incentives to keep utilizing paid news.
\end{abstract}

KEYWORDS: journalism, PR, paid news, professionalism, Central and Eastern Europe.

\section{INTRODUCTION}

This article focuses on a particular aspect of the more general practice of ethically dubious PR; so-called "paid news". Paid news is the practice of individual journalists and/or news organizations taking money (often offered through the intermediary of a PR professional or PR company, or an advertising agency) to write puff pieces for businesses or political interests without indicating that the content is in fact paid for, i.e. a form of corruption of both journalism and PR. Other terms used are "hidden advertising" or "advertorials" (Bærug, 2005; Erjavec, 2004; Erjavec \& Kovačič, 2010).

When viewed in the context of the ongoing discussion of journalistic professionalism and professionalization in the post-communist states (e.g. Aumente et al., 1999; Gross, 1996; Štetka \& Örnebring, 2013), the practice of black PR must be considered an extreme example of "unprofessional" practice, both for journalists and for PR professionals, and also almost regardless of how one defines journalistic professionalism. Offering/accepting money for favorable coverage in a non-transparent way violates professional norms of journalists and PR professionals alike. 
A key theme in the referenced literature on journalism in post-communist nations is the relatively weak professionalism among journalists, i.e. little agreement on ethical principles, low degree of commitment to ethical practices, and a low degree of formal organization. The continued existence of the practice of paid news can certainly be seen as a sign of a continued weakness of professionalism among journalists - and among PR professionals, despite a clear trend towards professionalization in that field as well (Olędzki, 2011). There is some discussion of professional standards and of a "professional model" vs a "craft model" of PR (e.g. Karadjov et al., 2000) as well as of professional ethics among PR practitioners (Olędzki, 2011), but in general the discourse of "professionalism" has not been applied in studies of PR professionals in the region. Still, regardless of how "professionalism" and "professional standards" are defined within the PR field, most practitioners would likely agree that paying money to journalists "under the table" for favorable, non-transparent coverage, constitutes unprofessional conduct.

In light of the fact that journalists and PR practitioners alike aspire to professionalism and want to be seen as professional (in the general sense of the word), it is of interest to further study the "unprofessional" practice of paid news from a professionalization perspective. This paper presents an overview of existing studies on the practice and offers some exploratory observations based on empirical data that was gathered in the region as part of the larger research project "Media and Democracy in Central and Eastern Europe" (University of Oxford, 2009-2013).

\section{PAID NEWS: AN OVERVIEW OF THE PHENOMENON}

There can be no doubt that the practice of paid news/black PR exists across many countries of Central and Eastern Europe. Bærug noted in his comparative study of the phenomenon that the practice is forbidden by law in Estonia, Latvia and Lithuania (Bærug, 2005, pp. 58f), and most of the 10 countries studied here have similar provisions either in their general Media Laws or in their Advertising Laws. In his study, Bærug interviewed and surveyed TV journalists in Latvia, Lithuania and Norway and found that Latvian and Lithuanian TV journalists ${ }^{1}$ were more likely to believe that their colleagues would engage in the practice than were Norwegian journalists (Bærug, 2005, p. 61). Bærug also employed a control method in one of the countries (Latvia), where he or his assistants called various TV program editorial teams and posed as a representative of a company interested in buying access to the news: out of 34 programs across the five major TV channels, representatives for 19 of them answered that they would be willing to do this, and 14 said they did not (the one remaining program representative gave an answer impossible to classify as a yes or no) (Bærug, 2005, pp. 62f).

1 The study also notionally included Estonian TV journalists but as only 4 of them were interviewed Estonia was excluded from the presentation of results. 
Erjavec has extensively studied the phenomenon of "advertorials", as she terms it (following Cameron \& Ju-Pak 2000), in Slovenia (Erjavec, 2004, 2005; Erjavec \& Kovačič, 2010). The latter study (e.g. Erjavec \& Kovačič, 2010) in particular focuses on the production process behind paid new. The study clearly demonstrates that the practice of hidden advertorial production was sufficiently established that the researchers could get access to news organizations in order to conduct participant observation of the advertorial production process, as well as to get some 90odd informants from journalism, advertising and PR to talk about the practice in detail. The researchers could reveal the fact that hidden advertorial production was often included in formal contracts between media outlets and advertisers (Erjavec \& Kovačič, 2010, pp. 98f).

Harro-Loit \& Saks' study of increased commercialization and increased integration of advertising and editorial practices in Estonia found that it was common in the magazine sector to offer positive editorial material as part of a package deal for advertisers (Harro-Loit \& Saks, 2006, pp. 319f), a formalization of the practice of paid news. However, the same study found that this practice was largely confined to the magazine sector (which of course includes many publications with a clear focus on consumption, e.g. travel magazines, motor magazines and technology magazines) and that the national daily newspapers were much more negative (but not wholly negative) to the practice (Harro-Loit \& Saks, 2006, pp. 319f).

Finally, in a Transparency International survey of corporate representatives in Lithuania, respondents were asked if they in the past year had provided payment to media outlets for favorable coverage (or the withholding of unfavorable coverage) that could not be considered advertising. Responses were divided by media type, and between 7 and 12 per cent of respondents said that they had done so $(n=502$; see Transparency International Lithuania, 2007, p. 10). Another study of the Lithuanian case (Nevinskaite, 2009) highlights the role of EU structural funds in the production of paid news. EU structural fund projects contain requirements to publicize the project, which means that in such projects there is a pool of money relatively easily available for both hidden and open advertorial production - a practice that is also actively encouraged by newspapers and magazines who see the EU money as an extra source of income (Nevinskaite, 2009, p. 161). One should also note that in the case of Lithuania, the practice of paid news has been independently corroborated through the WikiLeaks embassy cables. These leaked documents describe Lithuanian businessmen complaining to the US Embassy about being "blackmailed" by leading news organizations in order to provide (non-transparent) advertising money (BNN, 2011).

\section{PREVIOUS RESEARCH ON PAID NEWS: AN ASSESSMENT}

Three key points emerge from previous studies of paid news in Central and Eastern Europe. First, that the interest has been more on the journalism side of the equation 
than on the PR side. The possible exception is the Erjavec and Kovačič study, where advertisers and marketing agents are studied to the same extent as journalists (it is clear from the context that even if Erjavec and Kovačič refer to "advertisers", PR professionals must be involved in the practice, too). Nevinskaite also notes that lack of commitment to ethics among PR professionals is a factor but still focuses on the journalism side (Nevinskaitè, 2009, p. 160).

Second, there a kind of "ethical continuum" of paid news. The practices HarroLoit and Saks describe in their study (i.e. blurring of the line between advertising and editorial material in the specialist magazine sector) are not fundamentally different from what goes on the specialist magazine sector in Western European countries, whereas the practices described by Bærug and also Erjavec and Kovačič are closer to what could be defined as outright corruption.

Third, and perhaps most importantly, when attempting to explain why the practice exists, most studies highlight and focus on the limited commitment to professional ethics on the part of journalists and media organizations (e.g. Bærug, 2005, p. 88, Harro-Loit \& Saks, 2006, pp. 320f; Nevinskaitè, 2009, pp. 159f), but some also note other factors, like the low salary and low social status of journalists as well as the limited financial resources of media organizations (Bærug, 2005, p. 89; Erjavec \& Kovačič, 2010, p. 104), the role of media owners, the role of advertisers and PR agents, and the role of the state (Erjavec \& Kovačič, 2010, pp. 105f), and - in the specific case of EU structural funds being used for paid news production - the role of the EU itself (Nevinskaitè, 2009, p. 161).

I would argue that the focus on the journalism side of the paid news phenomenon, as well as the emphasis on a lack of journalistic ethics as an explanatory factor, underplays the systemic nature of the practice and the fact that journalists and PR professionals alike are part of a common culture of corruption. In this, I take my inspiration from the comparative study of media systems as outlined by Hallin and Mancini (2004), the notion that culture is an important general explanatory factor when studying corruption (Lipset \& Lenz, 2000; Sandholtz \& Taagepera, 2005), and the anthropological use of the concept of clientelism in post-communist societies (Örnebring, 2012; Roudakova, 2008).

\section{PAID NEWS, NORMATIVE TRANSGRESSIONS, AND PROFESSIONALISM}

Paid news is a practice related to corruption and as such easily and intuitively classified as normatively wrong. However, within the study of corruption, scholars have noted that corruption is actually very difficult to define, and particularly to define in such a way that makes comparison between different cases and contexts meaningful (Bull \& Newell, 1997; Morris, 1991). There is not space within this brief article to re-open the long-standing debates on what "professional" and "professionalism" mean in journalism and in PR, but there is a need to clarify what kind of normative transgressions are actually involved in the practice of paid news. This will be done 
on a more general level, and I will make the case that the normative transgressions involved are not quite the same for journalists and for PR professionals.

On the most general level, paid news violates the norm of transparency, i.e. that certain practices are seen as demanding a level of publicness and openness in order to ensure fairness and accountability. The norm of transparency is also related to the norm of fairness. Lack of transparency may not in itself be unfair but can hide unfair practices. The practice of paid news is hidden from the audience; it is not possible for even an informed reader to detect that what looks like a news item is in fact paid-for PR blurb. Transparency is in this instance also related to the norm of truthfulness present in both professions. While a paid news item may contain no lies, it is not truthful about its own origins. In journalism the combined norms of transparency and truthfulness are manifested in long-standing rules on the strict separation of editorial material and advertising, rules that paid news violates.

However, in the case of journalism, there are further normative transgressions created by paid news that are not as relevant to the PR field (not irrelevant, just not as relevant). First, according to the common normative framework of journalism, it would be a transgression of the norm of independence. This norm states that journalism should be independent from both state and commercial forces in its production of content. While commercial media are of course dependent on money from advertisers and subscribers, there is a widespread notion that this dependence should not in any way affect the production of news. This norm of independence does not have the same force in the PR profession. The normative transgression of paid news in the case of $\mathrm{PR}$ is not that the PR professional acts on behalf of their client (which is to be expected), but that it is done in a non-transparent manner.

Secondly, related to the norm of independence is the norm of neutrality: that journalism, perhaps particularly in the cases of politics and business, is not expected to favor one interest over another. Again, PR is different: the essential service that PR provides is to favor its clients' interests. As long as this is done in a truthful and transparent way, lack of neutrality is generally not seen as an issue. Note also that the PR profession as a collective in many nations has a strong professed (though not always acted upon) bias against negative PR. PR should be conducted with some measure of neutrality. Attacking rivals of your client is generally more frowned upon than presenting your client in a positive light.

All this is not to say that paid news is any less of a transgression in the PR profession than it is within journalism, merely to observe that the normative context of journalism is slightly more complex due to the prevalent notion that journalism has some kind of democratic role to play (a role generally not attributed to PR in the same way). It could, in all fairness, be said that journalism transgresses against the norm of transparency more often than does PR, as news production is a very non-transparent process.

Complicating this picture further is the fact that norms - and the norms of journalism in particular - are not universal, something that has been demon- 
strated by numerous comparative studies (e.g. Donsbach \& Patterson, 2004; Hallin \& Mancini, 2004; Hanitzsch, 2006; Weaver, 1998). The norm of independence is interpreted very differently in countries that have a strong party press tradition (Hallin \& Mancini, 2004, pp. 94f). Indeed, in their comparative analysis of media systems, Hallin and Mancini use the level of instrumentalization of the media as a key point of comparison, i.e. the degree to which the media are seen as instruments for other societal interests vs. the extent to which they are independent from such interests. Instrumentalization is by Hallin and Mancini taken primarily to mean the process by which (news) media are used to intervene in the political process, though they note that the funding-by-advertising model in itself can be seen as a form of instrumentalization (Hallin \& Mancini, 2004, p. 37). Instrumentalization is furthermore identified as a key factor that inhibits journalistic professionalism (Hallin \& Mancini, 2004, pp. 113f). This is precisely because independence is generally seen as a key professional norm, and instrumentalization is the opposite of independence.

Hallin and Mancini's concept of (political) clientelism is related to instrumentalization:

[clientelism is] ... a pattern of social organization in which access to social resources is controlled by patrons and delivered to clients in exchange for deference and various forms of support. (2004, p. 58)

Publicity, and by extension public opinion, are often viewed as such social resources, and patrons control (i.e. instrumentalize) media outlets in order to secure positive publicity for themselves and negative publicity for their rivals (Roudakova, 2008, p. 43). Patron-client relationships can manifest themselves on different levels - between individuals, between organizations, between institutions as a whole (Örnebring, 2012).

I argue that the overall levels of media instrumentalization and political clientelism in a country are important explanatory factors for the continued existence of paid news/black PR. Instrumentalization contributes to an environment where the (news) media are used by different interests to reach an audience and ideally influence it. Extensive clientelism in a given country may also contribute to an environment where the professional value of independence becomes more difficult to maintain (Roudakova, 2008; Örnebring, 2012).

\section{EMPIRICAL MATERIAL}

As part of the overall project "Media and Democracy in Central and Eastern Europe", a large number of semi-structured in-depth interviews were conducted with journalists, politicians, senior editors, media regulators, PR professionals, political communicators and various experts in each of the ten countries studied, in the period of 2010-2012. Interviews were between 30 minutes and $1 \mathrm{~h} 30$ minutes in 
length. The total number of interviewees in each country ranges between 30 and 40. However, as paid news was merely one of many areas covered by this project, many categories of interviewees were not asked about this practice. For this article, a smaller number of interviews have been used as empirical material, focusing on three categories of actors: journalists, PR professionals (which includes political communicators) and other relevant actors (academic experts on journalism and/or PR, anti-corruption experts, members of journalistic ethics committees, anti-corruption activists). All interviewees were asked either directly about the prevalence/ practice of paid news, or provided context both on the general nature of corruption and on media-related corruption in the respective country. The total number of interviews forming the basis of this article is 164 (see Table 1).

Table 1. Conducted elite interviews (Total $N=164$ )

\begin{tabular}{|l|r|r|r|r|r|r|r|r|r|r|}
\cline { 2 - 12 } \multicolumn{1}{c|}{} & BG & CZ & EE & HU & LT & LV & PL & R0 & SI & SK \\
\hline Journalists & 5 & 4 & 4 & 2 & 7 & 11 & 8 & 4 & 4 & 3 \\
\hline PR professionals & 4 & 6 & 5 & 5 & 9 & 8 & 5 & 4 & 4 & 6 \\
\hline Other actors & 3 & 3 & 5 & 6 & 6 & 7 & 8 & 5 & 5 & 6 \\
\hline Total for country & 12 & 13 & 14 & 13 & 22 & 26 & 21 & 14 & 14 & 15 \\
\hline
\end{tabular}

Source: author.

The sample numbers may appear erratic but this is largely a function of breaking out a smaller number of interviews from a larger sample. In some countries (notably Hungary), fewer journalists in total were interviewed, which also results in fewer interviews touching upon the paid news phenomenon. The division of labor within the overall project (in total five research fellows over four years, whose appointments did not fully overlap, plus two research assistants) also made it necessary to select certain countries to focus on in relation to different aspects of the project. In the case of paid news (which formed part of the wider project area relating to journalistic professionalism), Latvia, Lithuania and Poland were for example selected for more in-depth study, hence the larger number of interviews in these three countries.

Even though the sample can be considered robust in qualitative terms (i.e. it does provide a good overview of the issue of paid news from the perspectives of two categories of practitioners as well as external experts), it is also clear that the small number of interviews in the individual countries makes the sample unsuitable for in-depth comparative analysis. The 164 interviews are thus rather treated as a crosssectional sample of journalists and PR professionals in post-communist Central and Eastern Europe in general; any comparative points made should be considered tentative and exploratory in character.

The methodological difficulties created by the hidden nature of corruption are well known (Bull \& Newell, 1997; Lancaster \& Montinola, 1997). Therefore, asking 
some preliminary and exploratory questions of the interviewees on the existence, nature and general character of the practice of paid news made methodological sense - one may need to build trust with interviewees over a longer period of time, and it was important to first assess exactly how sensitive the issue is in a given country context. None of the studies cited earlier highlighted any specific methodological issues, but in those cases participation was anonymous. In the present project, respondents were as a rule asked to be on the record and not guaranteed anonymity as a matter of course (though all quotes in this particular article have been anonymized).

\section{PAID NEWS IN PRACTICE: EXPLORATORY OBSERVATIONS}

Interviewees across all countries agree with the most basic finding of existing research: that the practice of paid news exists. The only exception was Estonia, where respondents were generally insistent that the practice did not exist, or at least was very limited (in all other country cases, interviewees conceded that the practice existed, though they may have disagreed as to how widespread it was):

I know that this practice is known in Latvia, but here in Estonia you cannot really do it. (Estonian journalist)

In Estonian media, you can't buy articles. That's definite. Of course, because of the recession, there are now more contacts between advertising departments and editorial [in newspapers], but these are not direct links. [...] So no "empty news" in Estonian newspapers. (Estonian PR professional)

These answers contradict Harro-Loit and Saks' article (Harro-Loit \& Saks, 2006), though as noted, most of the practices described there are not substantially different from what you would find in any other European country. Some Estonian interviewees in the present study noted that such "freebies" exist but that paid news in the stricter sense of $\mathrm{PR}$ companies paying journalists to either produce or publish PR texts in the guise of editorial texts does not. This illustrates the "ethical continuum" of paid news where certain types of freebies in certain types of journalism (notably lifestyle journalism) are viewed as more OK or even normal, whereas paid news in other areas (e.g. business journalism) is viewed as an obvious normative transgression. Given that Estonia also has lower levels of general corruption than the other nine countries in the study (Sandholtz \& Taagepera, 2005, p. 131), it is likely that the assertions of Estonian interviewees have some basis in reality, i.e. that the practice of paid news is less widespread in that country.

Another circumstance that has not been taken into account in previous studies is that journalism and PR in the region are not always separated. There are many cases of journalism and PR being functionally integrated on the level of the individual practitioner, i.e. that a freelancer may work on journalism one day and then PR copy the next, or even hold parallel (part-time) jobs in both sectors. This was 
mentioned by interviewees in Latvia, Lithuania and Romania, and has been studied in the case of Slovenia (see Krašovec \& Žagar, 2009, pp. 93f). Both journalistic professionalism and PR professionalism will be more difficult to maintain if these two occupations are not clearly separable. Some interviewees made observations in this direction:

INT: Do you have guidelines on working in PR and in journalism simultaneously? What are these guidelines? Are they followed? What are the sanctions (if any) if the guidelines are not followed?

A: PR professionals must not enhance corruption, i.e., they must not "buy" journalists. They may of course hire a journalist and pay a decent honorarium for writing an article, but this honorarium may not be too high. One may work both as a PR professional and a journalist if he or she does not break other rules. For example, one may write articles and offer them to newspapers for publication.

INT: What if one as a journalist writes an article in a seemingly independent manner of a company while at the same time working for the same company as a PR advisor?

A: This is unethical, but in this case one breaches journalism ethics, not PR ethics. The job of a PR professional is to feed journalists with information. Then it is the journalists' job to use that information. (A = Hungarian PR professional, INT = interviewer)

\section{Another example from Romania:}

INT: Is the Romanian journalism community divided politically?

B: Yes. But the main problem is that it is ethically divided. Some journalists make a lot of money in unethical ways.

INT: Can you give me an example?

B: Especially in the area of advertising, that is to say they produce unmarked advertisements, especially in the 1990s when rules were very "soft" in the field. They produced advertorials. (B = Romanian journalist, INT = interviewer)

\section{And also in the following example from Poland:}

But in relation to our Code, we have in the Chamber a Collegiate Court that can rule on internal complaints. And this Court has looked into such cases, such complaints. There was even one case where one publisher threatened to sue another if they did not cease accepting paid news like this. So it is discussed and dealt with internally. (Polish journalist/editor)

In Bulgaria, the Journalist Union even has a special section for those journalists who also work in PR, demonstrating how established the integration of the two occupations is (the Bulgarian PR professional quoted below was very critical of this practice):

There is one strange bird in the PR life of Bulgaria: the PR society of the Union of the Bulgarian Journalists. We oppose the existence of such a body, but we cannot do anything about it. Their 
members are very important people. They very much insist that this organization is respected, and argue that there is a place for it among the Union of Bulgarian Journalists. This is something I do not support, with the concept that there could be a PR branch of the unions, I oppose it from the professional point of view. I do not agree that PR and journalism is one and the same thing; I categorically do not agree that PR is media relations; I don't even think that PR is something that should be on the first page of a newspaper. (Bulgarian PR professional)

The fact that journalists also work in PR has to do with the generally low salary level of journalism across Central and Eastern Europe, as well as with the relatively high degree of job insecurity and lack of permanent jobs (Erjavec \& Kovačič, 2010, pp. 103f; Głowacki, 2015, pp. 77, 85). PR is normally better paid, which seems to lead to the PR or advertising side being the dominant one in paid news exchanges. The advertiser/PR actor generally has the initiative, takes the contact with the media, and selects the topics for the paid news items (Erjavec \& Kovačič, 2010, pp. 101, 103). However, low salary levels cannot solely explain the existence of an official "PR journalism" section within the Bulgarian Union of Journalists. It could be viewed as another indicator of the functional integration of the two occupations and by extension of the partial existence of a common professional culture.

Paid news is generally perceived as more common in the specialist magazine sector:

But there are newspapers published for certain professions - business newspapers - like the Healthcare Newspaper, where it is impossible to place any news without paying for it. What will appear in the newspaper is decided by the head of the advertising department. This really upsets me a lot; it is disgusting. And it is common in the whole healthcare sector. The only way to change this practice would be if all companies agreed not to cooperate with such a medium... (Slovakian PR professional)

Some interviewees also suggested that there is a big difference between national and regional/local media in this regard. Regional and local media often have even scarcer resources than national media (particularly in the wake of the global financial crisis), and are often owned by local business/political interests who exert a more direct control over content.

\begin{abstract}
No. Individually, we are well paid. I make my living working only for the newspaper, and have a good social and material status. When it comes to the whole newspaper, our owners are very fair when it comes to our payments. However, the regional newspapers, that's a mess. They are constantly under economic and editorial pressure. They give them money by hand, some advertisers or businessmen can also decide what is going to be written in the newspaper, especially in times of elections. (Bulgarian journalist)
\end{abstract}

The following story from Lithuania is illustrative:

INT: It [i.e. the practice of paid news] is worse in local and regional media?

C: I have an interesting story on this actually, it was when we met with a Swedish newspaper that writes about media, I can't remember the name... 
INT: Medievärlden [The Media World]?

C: Something like that, yes. We were meeting with them in Stockholm and we started to talk about the role of media here in Lithuania. And they were looking at us like we were people from another planet! And I said, yes, it is really true [i.e. that you can pay local papers to get favorable coverage], and the same applies to Swedish companies, like banks for example. When a Swedish bank comes here, they have to deal with the media somehow. They come from a normal country, with normal traditions, with a normal level of transparency, and they have written down in their ethical guidelines that they can't do this [i.e. pay for articles]. But when they come here, it is a rule, it is tradition. A structure. And you are going into a small town, you open a branch there, and you want to somehow deal with the media, because you want them to cover your opening, to spread some information to people. Then you have two choices. Either to pay, and be visible, or not to pay, and not be visible [laughs]. Swedish banks must have very different strategies then! They are forced to do it. This is very interesting. ( $\mathrm{C}=$ Lithuanian PR professional $1, \mathrm{INT}=$ interviewer)

One Lithuanian PR professional provided the most detailed account of how paid news works in practice, and s/he freely admitted buying favorable coverage from several news outlets:

INT: So you can also pay to not have information published? So there is positive, negative [publicity], like suppression.

D: So usually positive and negative, it's very expensive. So usually you pay for the silence and then you can pay for the positive. So you pay for each article. For example, we have a contract with all the main newspapers and if we want a positive article, I am calling the newspaper. Sometimes I write myself, sometimes they write. And they publish and you get the bill. It's very simple. Now to buy an article in the newspaper, it's something like going to the shop to buy milk. ( $\mathrm{D}=$ Lithuanian PR professional 2, INT $=$ interviewer)

Previous studies have generally focused on a particular media type (e.g. television journalism, specialist magazines) or talked more generally about national media, but the differences between national and regional/local media have not been extensively investigated. This is potentially an important area for future research, especially in light of other research on local government and corruption in postcommunist countries (e.g. Karklins, 2005; Melvin, 2002; Sharafutdinova, 2007).

Finally, EU Structural Fund Project resources play an important role for paid news production in all the countries where such projects are common, not just in Lithuania, and the observations of Nevinskaite are borne out by other Lithuanian interviewees. First, it must be described in a bit more detail exactly how and why EU Structural Funds have come to play this role - the following presentation is largely based on Nevinskaitè (2009, pp. 153ff).

EU Structural Fund projects are bound to spend resources on publicity and have a budget line for public information. The regulations surrounding public information from the projects are very strict in terms of form and content (e.g. the placement of logos, information on the project) but have no requirements as to the general principles of communication. If a journalist independently researches a project 
and publishes an article on it, this is not likely to count towards the publicity requirements (as the journalist will likely not want EU logos in the article), and if a journalist has already written an article independently then he/she is less likely to write about the project again based on a press release. Thus project managers often factor in the cost of paid articles instead, as this meets the EU-imposed needs for strict control over visual presentation and also guarantees the coverage necessary according to the publicity requirements.

In the Lithuanian case, this is further complicated by the fact that the state, specifically the Ministry of Agriculture (which is the recipient of the majority of EU Structural Funds in Lithuania) is also the largest advertiser in the country (the second-largest advertiser is the supermarket chain Maxima; World Association of Newspapers, 2010). The common perception in Lithuania is that successive Ministers of Agriculture have used EU Structural Fund money to buy paid news in order to boost their own political profiles (Nevinskaite, 2009, p. 158). The following exchange mentions this:

INT: Have there been any high-profile public cases of hidden advertising, where the practice has become public knowledge?

E: Yes, about five years ago, there was a case where the Ministry of Agriculture had a budget line for public relations, and the Minister of Agriculture, she used this money to buy full-page ads in Lietuvos rytas and Respublika where she essentially just promoted herself. Paid by public money. It was notionally ads about agriculture but in reality they were just raising the profile of her as a Minister. That was debated at the time.

INT: How much is the state involved in the advertising business, then?

E: A lot. Through ministries.

INT: So the ministries would use their PR budgets to buy advertising, both hidden and open? As a rule, or some ministries more than others?

E: In general. They would organize a public tender to manage an information campaign on some public issue, a PR company would win the tender, and then they would use some money for open advertising in newspapers, and some for hidden advertising.

INT: Does that mean that the state or ministries can put pressure on media outlets, through this PR money?

E: Not really the government as a whole, it is more individual ministers who use this money to raise their profile. $(\mathrm{E}=$ Lithuanian media expert, $\mathrm{INT}=$ interviewer $)$

That EU Structural Funds can play a similar role is also mentioned by one of the Bulgarian interviewees:

Then it turns out that in the case of Bulgaria the country has been severely hit by the economic crisis, so the only real money is with the government. And the government found a very sophis- 
ticated way to influence the media through this money, because it is being distributed through the Operational Funds of the EU [this is the same as the Structural Funds], which are programs mostly financed by the EU but also partly by the national government, and this money is often used for actions for publicity and informing the public about certain activities. And of course during the previous government [until July 2009] most of this money was channeled through a couple of big PR agencies, which subsequently were distributing the money to certain media, so if you wanted to get a chunk of these funds then of course you had to be careful what you were writing about... (Bulgarian media expert)

\section{CONCLUSIONS AND AREAS OF FURTHER RESEARCH}

The review of the existing research and the interviews point to two key factors explaining the persistence of the practice of paid news across Central and Eastern Europe that go beyond the fairly generic "lacking journalistic ethics" explanation that has been the dominant one in the literature so far. One, the functional integration between journalism and PR in most of the countries studied, especially in the wake of the financial crisis of 2008-09. Occupational overlap on the level of the individual practitioner is relatively common as many freelancers work simultaneously in journalism and PR. This functional integration stretches beyond the areas of journalism where it has been common for a long time, i.e. different types of lifestyle journalism like travel journalism and technology journalism. Still, lifestyle journalism is the area where the overlap between journalism and PR is the greatest in Central and Eastern Europe as elsewhere. This can be viewed as a function of the increasing commercialization of news media in Central and Eastern Europe (e.g. Dobek-Ostrowska, 2015). The integration of journalism and PR both on an individual level and on an organizational level is a de-professionalizing influence on both occupations: if there is no practical difference between producing journalism and producing PR content, there is no need for separate and explicit ethical guidelines (that people would expect to follow) in either occupation.

Second, previous research and interviews indicate a degree of complicity between journalists and PR professionals and a shared culture of corruption that is linked to clientelism. Neither side has strong incentives to stop the practice, and both sides have stronger incentives to keep the practice up (as indicated by Erjavec, \& Kovačič, 2010). As one Lithuanian interviewee noted, the newspapers get more money and the politicians/businessmen get positive coverage - everybody wins except the citizens. "Professionalization" would mean loss of an important additional source of income for individual journalists as well as media organizations, and loss of an important and non-transparent channel of communication for PR professionals and advertisers. Continued instrumentalization could be viewed as not only economically but also culturally rational: the more both parties (i.e. journalists and PR professionals) accept the practice then the less likely it is that cultural sanctions (from public/professional disapproval all the way to ostracism) will be applied. 
Further research into the phenomenon of paid news in Central and Eastern Europe would need to cover in more detail the extent and nature of occupational overlap between journalism and PR, as well as the nature and practices of this shared culture of corruption. It is also necessary to further study differences between national media and regional/local media, and the role of EU Structural Fund project grants in paid news production; two areas that have emerged as potentially important from this article but which could not be covered in detail within the scope of the present study.

\section{REFERENCES}

Aumente, J., Gross, P., Hiebert, R., Johnson, O., Mills, D. (1999). Eastern European Journalism: Before, During and After Communism. New York: Hampton Press.

Bærug, R. (2005). Hidden advertising and TV journalism in the Baltic countries and Norway. In: Bærug, R. (ed.). The Baltic Media World. Riga: Royal Ministry of Foreign Affairs of the Kingdom of Norway, pp. 58-89.

BNN (2011). WikiLeaks: Lithuanian media blackmail businessmen. BNN (Baltic News Network). Article published October 11, 2011. Retrieved October 10, 2015 from http://bnn-news.com/ wikileaks-lithuanian-media-blackmail-businessmen-38533.

Bull, M.J., Newell, J.L. (1997). New avenues in the study of political corruption. Crime, Law \& Social Change, 27 (3-4), pp. 169-183.

Cameron, G.T., Ju-Pak, K.H. (2000). Information pollution? Labelling and format of advertorials. Newspaper Research Journal, 21 (1), pp. 65-77.

Dobek-Ostrowska, B. (2015). Journalism and commercialization. In: Nygren, G., Dobek-Ostrowska, B. (eds.). Journalism in Change: Journalistic Culture in Poland, Russia and Sweden. Frankfurt am Main: Peter Lang, pp. 211-231.

Donsbach, W., Patterson, T.E. (2004). Political news journalists: Partisanship, professionalism, and political roles in five countries. In: Esser, F., Pfetsch, B. (eds.). Comparative Political Communication: Theories, Cases and Challenges. New York: Cambridge University Press, pp. 251-270.

Erjavec, K. (2004). Beyond advertising and journalism; Hybrid promotional news discourse. Discourse \& Society, 15 (5), pp. 553-579.

Erjavec, K. (2005). Hybrid public relations news discourse. European Journal of Communication, 20 (2), pp. 155-179.

Erjavec, K., Kovačič, M.P. (2010). Relations with the media: Who are the main actors in an advertorial production process in Slovenia? Journalism, 11 (1), pp. 91-109.

Głowacki, M. (2015). Who is a journalist today? Mapping selected dimensions for comparative study on journalism. In: Nygren, G., Dobek-Ostrowska, B. (eds.). Journalism in Change: Journalistic Culture in Poland, Russia and Sweden. Frankfurt am Main: Peter Lang, pp. 63-95.

Gross, P. (1996). Mass Media in Revolution and National Development: The Romanian Laboratory. Ames, IA: Iowa University Press.

Hallin, D.C., Mancini, P. (2004). Comparing Media Systems: Three Models of Media and Politics. Cambridge: Cambridge University Press.

Hanitzsch, T. (2006). Mapping journalism culture: A theoretical taxonomy and case studies from Indonesia. Asian Journal of Communication, 16 (2), pp. 169-186.

Harro-Loit, H., Saks, K. (2006). The diminishing border between advertising and journalism in Estonia. Journalism Studies, 7 (2), pp. 312-322.

Karadjov, C., Kim, Y., Karavasilev, L. (2000). Models of public relations in Bulgaria and job satisfaction among its practitioners. Public Relations Review, 26 (2), pp. 209-218. 
Karklins, R. (2005). The System Made Me Do It: Corruption in Post-Communist Societies. New York: M.E. Sharpe.

Krašovec, P., Žagar, I.Z. (2009). Divisions and struggles of the Slovenian journalistic guild: A case study of contemporary European journalism. Journalism Studies, 10 (1), pp. 85-99.

Lancaster, T.D., Montinola, G.R. (1997). Toward a methodology for the comparative study of political corruption. Crime, Law \& Social Change, 27 (3-4), pp. 185-206.

Lipset, S.M., Lenz, G.S. (2000). Corruption, culture, and markets. In: Harrison, L.E., Huntington, S.P. (eds.). Culture Matters: How Values Shape Human Progress. New York: Basic Books, pp. 112-124.

Melvin, N.J. (2002). Patterns of centre-regional relations in Central Asia: The cases of Kazakhstan, the Kyrgyz Republic, and Uzbekistan. In: Hughes, J., Sasse, G. (eds.). Ethnicity and Territory in the Former Soviet Union: Regions in Conflict. London: Frank Cass, pp. 165-193.

Morris, S.D. (1991). Corruption and Politics in Contemporary Mexico. Tuscaloosa, AL: University of Alabama Press.

Nevinskaite, L. (2009). EU structural funds' publicity and the practice of journalism and public relations in Lithuania. Central European Journal of Communication, 2 (2), pp. 149-164.

Olędzki, J. (2011). Public relations without ethics will face the same fate as propaganda. Research reflections (Case study of PR associations in Poland). Central European Journal of Communication, 4 (1), pp. 141-155.

Örnebring, H. (2012). Clientelism, elites, and the media in Central and Eastern Europe. The International Journal of Press/Politics, 17 (4), pp. 497-515.

Roudakova, N. (2008). Media-political clientelism: Lessons from anthropology. Media, Culture \& Society, 30 (1), pp. 41-59.

Sandholtz, W., Taagepera, R. (2005). Corruption, culture, and communism. International Review of Sociology, 15 (1), pp. 109-131.

Sharafutdinova, G. (2007). Why was democracy lost in Russia's regions? Lessons from Nizhnii Novgorod. Communist and Post-Communist Studies, 40 (3), pp. 363-382.

Štetka, V., Örnebring, H. (2013). Investigative journalism in Central and Eastern Europe: Autonomy, business models, and democratic roles. The International Journal of Press/Politics, 18 (4), pp. 413-435.

Transparency International Lithuania (2007). Promoting greater media transparency. Research report. Vilnius: TI Lithuania. Retrieved October 10, 2015 from http://www.transparency.lt/new/ images/tils_media_final_eng.pdf.

Weaver, D.H. (ed.) (1998). The Global Journalist: News People Around the World. Cresskill, NJ: Hampton Press.

World Association of Newspapers (2010). World Press Trends 2010. Paris: WAN. 